\title{
Effect of Applying Techniques and Polymer Content on Strength and Drying Shrinkage of Glass Fiber Reinforced Concrete
}

\author{
Ratthanan Ianleng ${ }^{1, *}$, and Thatchavee Leelawat ${ }^{1}$ \\ ${ }^{1}$ Department of Civil and Environmental Engineering, Mahidol University, Thailand
}

\begin{abstract}
The purposes of this study were to evaluate compressive strength, flexural strength, and drying shrinkage of Glass Fiber Reinforced Concrete (GFRC) applying different techniques and varying polymer content. Two groups of specimens were classified applying the techniques: sprayed and premixed methods. AR-Glass was used with fiber content of 3 to $4 \%$ by volume. GFRC was mixed and applied different techniques with proportions of Styrene Butadiene Rubber (SBR) content of $0 \%, 3 \%, 6 \%$, and $9 \%$ by weight of cement. Compressive and flexural strength tests were performed at 1 and 28 days. Drying shrinkage tests were measured up to 98 days. The results obtained showed that increasing the SBR content showed a lower compressive strength of GFRC for both sprayed and premixed techniques. In the other hand, 28-day flexural strength results of GFRC for both premixed and sprayed techniques were found to increase with increasing SBR content. The GFRC mixes using sprayed technique exhibited flexural strength higher than the corresponding mixes using premixed technique because of the two-dimensional layer of fiber alignment for the sprayed technique. Increasing the SBR content exhibited the lower drying shrinkage of GFRC. At the age of 98 days, the drying shrinkage of GFRC using 9\% SBR content was about $40 \%$ lower than that of GFRC using $0 \%$ SBR content.
\end{abstract}

\section{Introduction}

Glass Fiber-Reinforced Concrete (GFRC) is a cementitious composite material made up of mortar matrix and chopped glass fibers. GFRC is mainly used in exterior building façade panels and architectural precast concrete. The matrix can be made from cement, sand, and additives. The benefits for the use of GFRC are toughness, ductility, and reducing large cracks, when compared to normal reinforced concrete. Generally, alkali resistant glass (ARGlass) is selected for making GFRC to reduce the degradation of glass fiber due to alkaline content of cement [1-5]. The polymer latex admixture is commonly used to improve the flexural strength, workability, and toughness of GFRC [6]. Two GFRC fabrications were reviewed: namely premixed and sprayed techniques. The sprayed technique, using up to 5\% of fiber content, is commonly used to make GFRC. Increasing fiber content could improve

\footnotetext{
* Corresponding author: ratthanan.ian@gmail.com
} 
flexural strength of GFRC [7]. The production cost of GFRC using sprayed technique is higher than that of GFRC using the premixed technique. Nonetheless, the premixed technique was found to require a higher water demand to obtain the specified workability, when compared to the sprayed technique [8].

However, limited research was found that studied the comparison of engineering performance of GFRC using sprayed and premixed techniques. Therefore, the main aims of the study were to evaluate the effects of applying techniques and polymer content on the compressive strength, flexural strength, and drying shrinkage of GFRC.

\section{Experiment}

\subsection{Materials}

White Portland cement conforming to ASTM C150 was used in this research. The specific gravity of the cement was 3.15 . Silica sand was selected with the maximum nominal size of $0.84 \mathrm{~mm}$ (No.20).

Glass fiber, conforming to ASTM D578, was AR-Glass type obtained from Nippon Electric Glass. The composition of glass fiber was $61 \%$ of silicon oxides, $15 \%$ of sodium oxides, and $20.8 \%$ of zirconia oxides. Specific gravity of AR-glass was $2.74 \mathrm{~g} / \mathrm{cm}^{3}$.

Polymer admixture was a Styrene Butadiene Rubber (SBR). Infrared transmittance of SBR using Fourier Transform Infrared Spectroscopy (FTIR) is shown in Fig 1. Specific gravity of SBR was $1.02 \mathrm{~kg} / \mathrm{l}$. The water content of SBR used was $54.5 \%$.

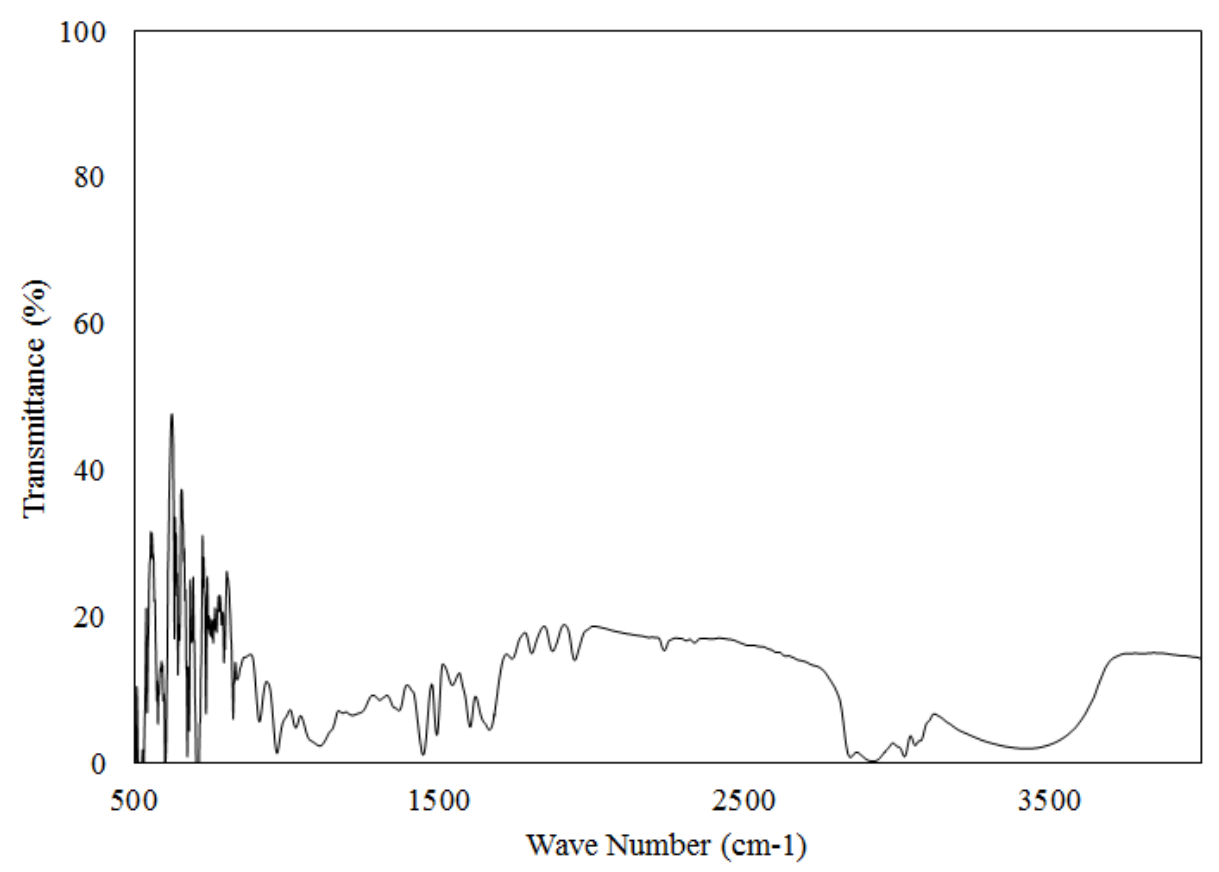

Fig 1. Infrared transmittance of SBR using Fourier Transform Infrared Spectroscopy (FTIR) 


\subsection{Mixing proportions and specimen preparation}

The summary of mix proportions for GFRC using sprayed and premixed techniques is given in Table 1. Six cylindrical specimens with the dimension of $\varnothing 100 \times 200$, six prismatic specimens with the dimension of $350 \times 150 \times 25 \mathrm{~mm}$, and three prismatic specimens with the dimension of $300 \times 75 \times 75 \mathrm{~mm}$ for each mix were prepared.

The compositions of GFRC using the premixed technique consisted of cement, sand, water, chopped glass fiber, and SBR. The GFRC samples were prepared by combining silica sand and white Portland cement in a mixer for 1 minute. Water and SBR were then added and mixed further for 1 minute. Thereafter, silica sand and white Portland cement, which were properly blended, were added into the mixer and mixed further for 5 minutes. The glass fiber with $3.5 \%$ by volume was then added and mixed for 2 minutes. The mixture was cast in the specimens as mentioned previously and vibrated using a vibrating table. It should be noted that the premixed technique could not prepare GFRC mixture without SBR content due to high water demand of glass fiber filaments leading to very low workability of GFRC mixes.

The GFRC specimens using sprayed technique were prepared by mixing silica sand and white Portland cement for 1 minute. Water and SBR were then added and mixed further for 1 minute. Thereafter, blended silica sand and white Portland cement were added into the mixer and mixed further for 5 minutes. The mixture was transferred to the container of the spraying machine and then continuously pumped through the spray nozzle of the spraying machine. The fiber roll was cut to nominal lengths of between 38 and $50 \mathrm{~mm}$ and then continuously fed through the mixture at the spray nozzle. The air pressure valve and pumping speed of the machine were adjusted to control the fiber content in the GFRC mixture within the range of 3-4\%. The GFRC mixture was then sprayed into the specimens as mentioned previously and consolidated using a tamping rod and vibrating table.

All of the specimens prepared were covered with plastic sheets. After 24 hours, the specimens were demolded and kept in a moist-cured room which was controlled at a temperature of $23^{\circ} \mathrm{C}$ and a relative humidity of $95 \%$ until the age of specimens were 28 days.

Table 1. Mix proportion of GFRC used in this research

\begin{tabular}{|c|c|c|c|c|c|c|}
\hline $\begin{array}{c}\text { Latex } \\
(\%)\end{array}$ & $\begin{array}{l}\text { White } \\
\text { Portland } \\
\text { Cement } \\
\left(\mathrm{kg} / \mathrm{m}^{3}\right)\end{array}$ & $\begin{array}{l}\text { Water } \\
\left(\mathrm{kg} / \mathrm{m}^{3}\right)\end{array}$ & $\begin{array}{c}\text { Silica } \\
\text { Sand } \\
\left(\mathrm{kg} / \mathrm{m}^{3}\right)\end{array}$ & $\begin{array}{c}\mathrm{SBR} \\
\left(\mathrm{kg} / \mathrm{m}^{3}\right)\end{array}$ & $\mathrm{W} / \mathrm{C}$ & $\begin{array}{c}\text { Fiber } \\
\text { content } \\
(\%)\end{array}$ \\
\hline $0 *$ & \multirow{4}{*}{930} & \multirow{4}{*}{372} & \multirow{4}{*}{930} & 0 & \multirow{4}{*}{0.45} & \multirow{4}{*}{$3-4$} \\
\hline 3 & & & & 28 & & \\
\hline 6 & & & & 56 & & \\
\hline 9 & & & & 84 & & \\
\hline
\end{tabular}

* Only for GFRC using sprayed technique

\subsection{Procedure and testing}

Flexural strength test, modified from ASTM C1018 [9], was performed at the testing ages of 1 and 28 days for the prismatic specimens with the dimensions of $350 \times 150 \times 25 \mathrm{~mm}$. The thickness of the specimens was adjusted from ASTM standard to be $25 \mathrm{~mm}$. The specimens were placed on the support of the universal testing machine where the specimens were 
loaded at their mid-point span. The displacement rate of the test was controlled at 1 $\mathrm{mm} / \mathrm{min}$ using "Merlin" software of the universal testing machine. The compression loads and displacements of the test were monitored. The flexural strength test of three specimens for each testing age was calculated.

Compressive strength test conforming to ASTM C39 [10] was performed at the testing ages of 1 and 28 days for the cylindrical specimens with the dimension of $\varnothing 100 \times 200 \mathrm{~mm}$. The specimens were loaded at a constant rate of 5. 3 kilo-Newton per second. The compressive strength test of three specimens for each testing age was calculated.

All of the specimens with the dimension of $300 \times 75 \times 75 \mathrm{~mm}$ for the drying shrinkage test were kept in the temperature- and humidity-controlled room which the temperature and relative humidity were controlled at $23^{\circ} \mathrm{C}$ and $50 \%$ respectively. The length changes of three prismatic specimens for each GFRC mix were measured starting from 1 day to 98 days. The shrinkage strains of the specimens were calculated.

\section{Result and discussion}

\subsection{Compressive strength of GFRC using sprayed and premixed techniques}

Fig 2 shows the compressive strength of GFRC varying the SBR content and using sprayed and premixed techniques. The compressive strength results of GFRC were found to decrease with increasing the SBR content for both premixed and sprayed techniques. The premixed technique exhibited slightly higher compressive strength than the sprayed technique because entrapped air voids were found to form in the cylindrical specimens using sprayed technique more than in the specimens using the premixed technique.

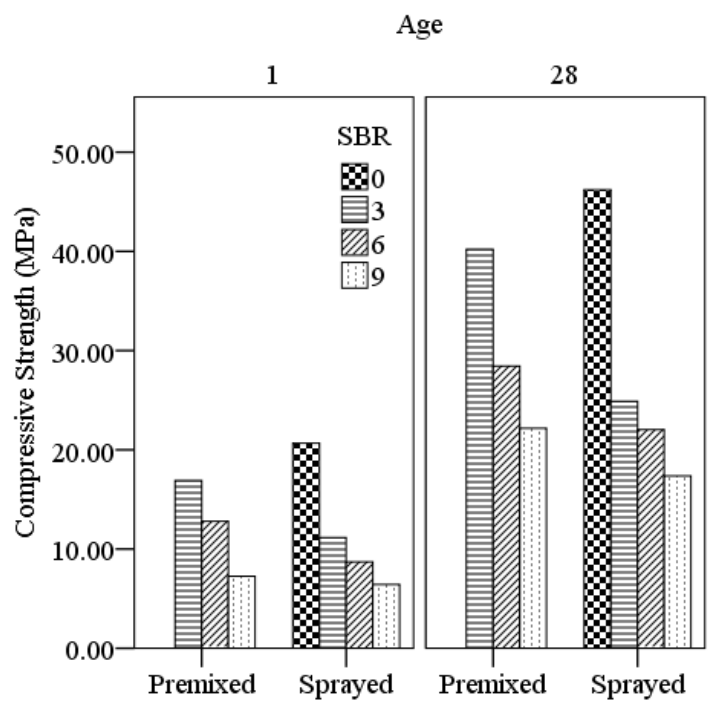

Fig 2. Compressive strength of GFRC using sprayed and premixed techniques

\subsection{Flexural strength of GFRC using sprayed and premixed techniques}

Fig 3 shows the flexural strength of GFRC varying the SBR content and using sprayed and premixed techniques. The results showed that GFRC specimens containing higher SBR content exhibited 1-day flexural strength lower than those containing lower SBR content. However, the 28-day flexural strength results of GFRC were found to be increased with 
increasing SBR content because the polymerization of SBR was developed at the later ages. In addition, the GFRC using the sprayed technique had slightly higher 28-day flexural strength than the corresponding premixed technique because the fiber alignment using sprayed technique was mostly found to be a two-dimensional layer which was different to the premixed technique as shown in Fig 4.

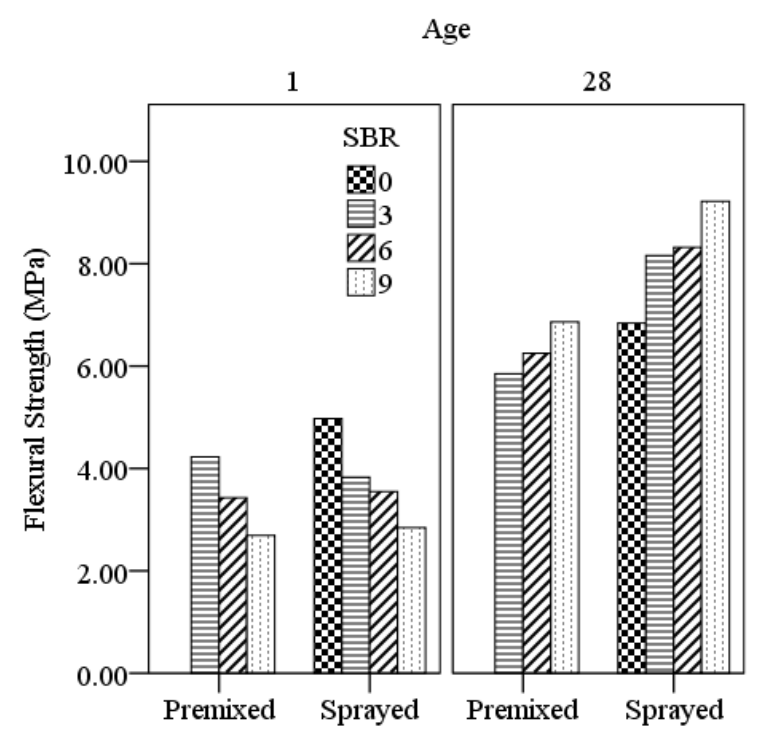

Fig 3. Flexural strength of GFRC using sprayed and premixed techniques

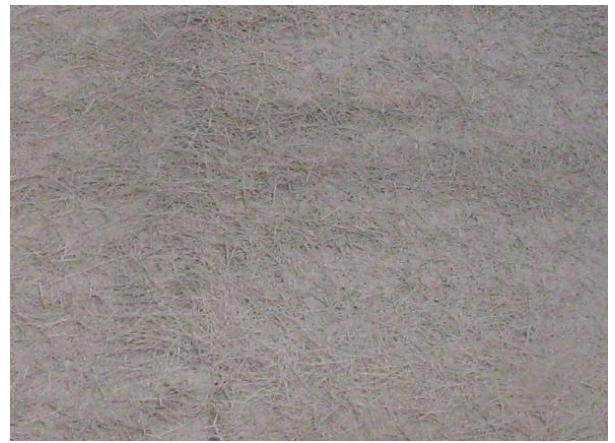

a)

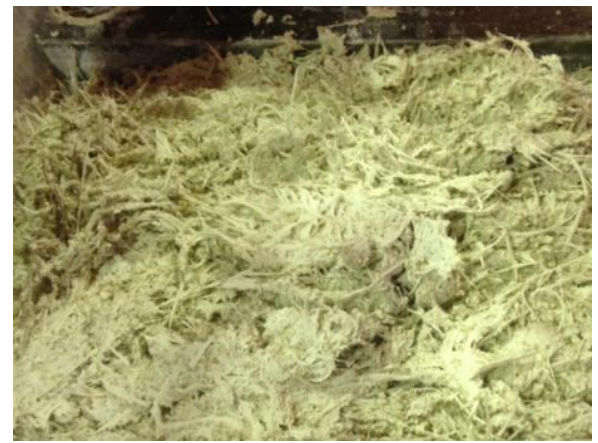

b)

Fig 4. Alignment of fiber filaments obtained from a) sprayed technique and b) premixed technique

Fig 5 shows the effect of the premixed and sprayed techniques on flexural and compressive strengths at the testing age of 28 days. The results showed that for a given compressive strength, the sprayed technique exhibited higher flexural strength of GFRC than the premixed technique. 


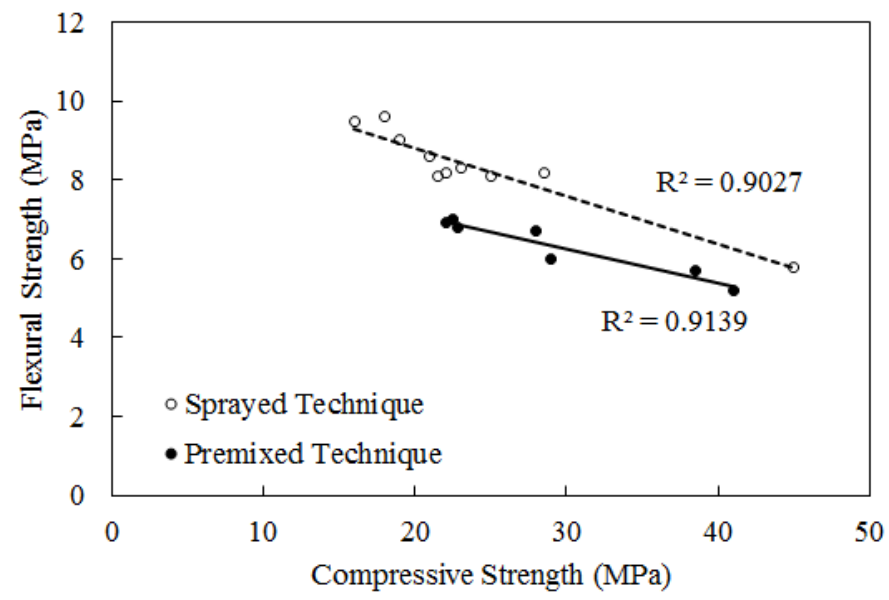

Fig 5. Effect of the premixed and sprayed techniques on flexural and compressive strengths of GFRC

In addition, the toughness value of GFRC using the sprayed technique with $9 \%$ SBR content was lower than that of GFRC with $6 \%$ SBR content, although the flexural strength of GFRC with $9 \%$ SBR content was higher than that of GFCR with $6 \%$ SBR content, as shown in Fig 6. The toughness values of GFRC varying with the SBR content and using premixed technique are shown in Fig 7. The toughness values of GFRC were found to increase with increasing SBR content. In addition, GFRC with 9\% SBR content using premixed technique was found to exhibit the highest toughness values of the I20 toughness index.

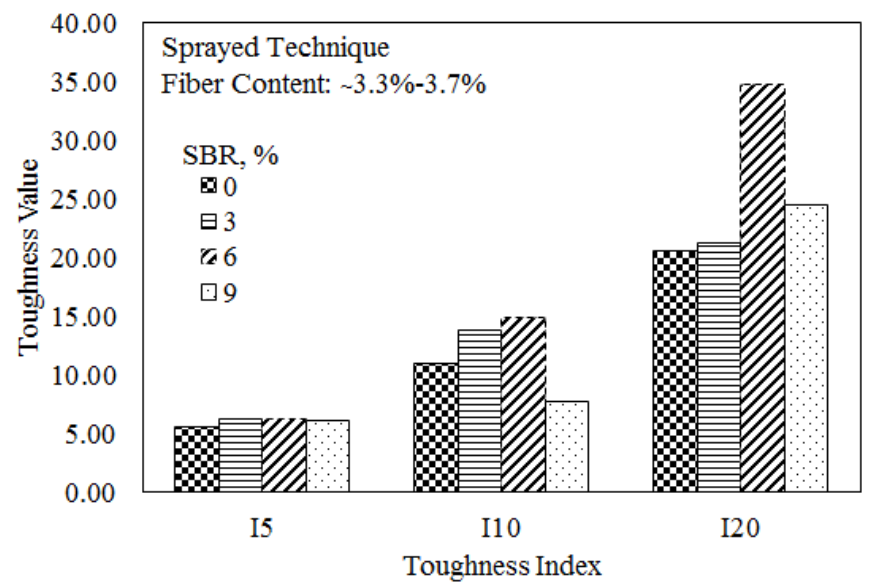

Fig 6. Toughness of GFRC using sprayed techniques and varying SBR content 


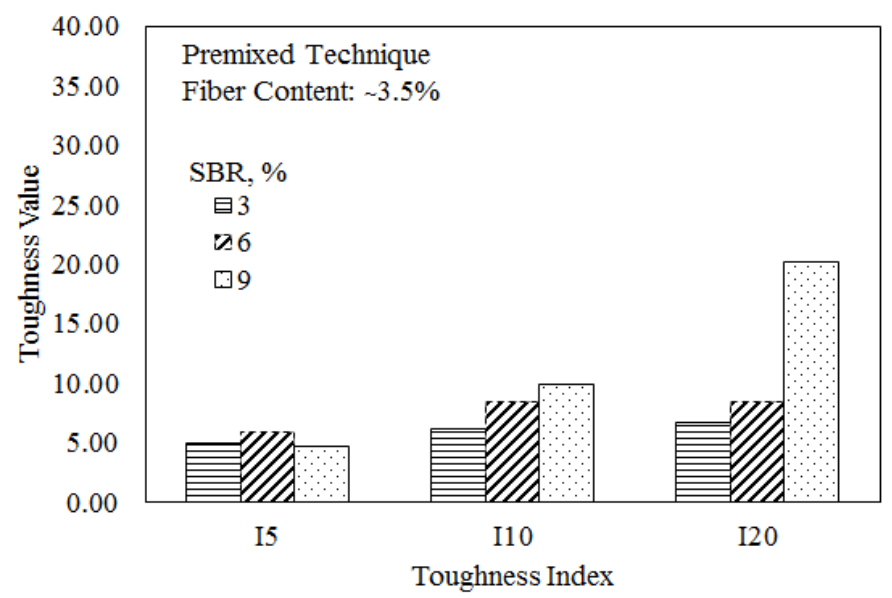

Fig 7. Toughness of GFRC using premixed techniques and varying SBR content

\subsection{Effect of polymer content on drying shrinkage of GFRC}

Fig 6 shows the drying shrinkage of GFRC varying the SBR contents and using sprayed and premixed techniques. The results showed that the shrinkage strains of GFRC were found to decrease with increases in the SBR content. At the testing age of 98 days, the shrinkage strain of GFRC containing 9\% SBR content was about $40 \%$ lower than that of GFRC using $0 \%$ SBR content. No significant difference in drying shrinkage results between GFRC using premixed and sprayed techniques could be observed.

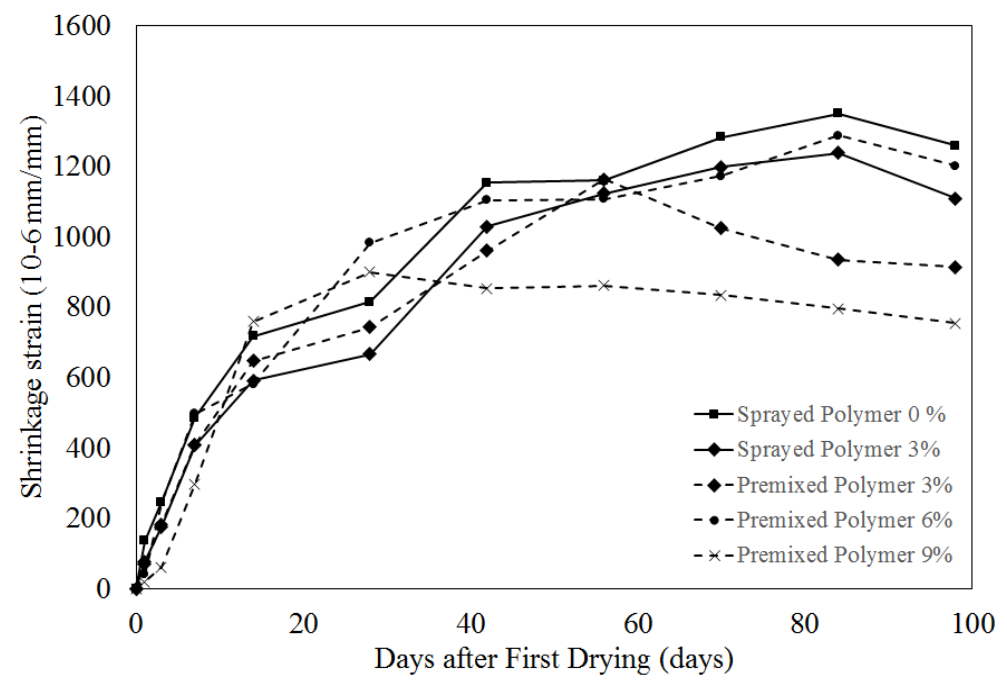

Fig 8. Drying shrinkage of GFRC with and without SBR and applying techniques 


\section{Conclusions}

- The 28-day compressive strength results of GFRC were found to decrease with increases in the SBR content for both premixed and sprayed techniques.

- The 28-day flexural strength results of GFRC were found to increase with increasing the SBR content for both premixed and sprayed techniques.

- The toughness values of GFRC using sprayed technique were higher than corresponding GFRC using premixed technique.

- The shrinkage strains of GFRC were found to decrease with increasing the SBR content.

- The optimum content of SBR latex was in the range of $6 \%$ to $9 \%$ for GFRC using sprayed technique.

\section{References}

1. A. J. Majumdar, R. W. Nurse, Glass fibre reinforced cement, Materials Science and Engineering, 15(2), 107-127 (1974)

2. D. Hull, an Introduction to Composite Materials, Cambridge Solid State Science Series (1981)

3. B. A. Proctor, B. Yale, A. R. Ubbelohde, G. Manfre, Glass fibres for cement reinforcement, 294 (1980)

4. A. J. Majumdar, Properties of GFRC. Fibrous Concrete (1980)

5. L. J. Larner, K. Speakman, A. J. Majumdar, Chemical Interactions between Glass Fibers and Cement, Journal of NonCrystalline Solids, 20, 43-74 (1976)

6. R. Wang, P. M. Wang, X. G. Li, Physical and mechanical properties of styrenebutadiene rubber emulsion modified cement mortars, Cement and Concrete Research, 35(5), 900-906 (2005)

7. A. L. Qureshi, A. Ahmed, an Investigation on Strength Properties of Glass Fiber Reinforced Concrete, 2(4), 2567-2572 (2013)

8. A. Bentur, \& S. Mindess, Fibre Reinforced Cementitious Composites, 2, 289-290 (2006)

9. ASTM, ASTM C1018 Standard Test Method for Flexural Toughness and First-Crack Strength of Fiber-Reinforced Concrete (Using Beam With Third-Point Loading), 100 Barr Harbor Drive, PO Box C700, West Conshohocken, PA, United States (2007)

10. ASTM, ASTM C39 Standard Test Method for Compressive Strength of Cylindrical Concrete Specimens., ed. 100 Barr Harbor Drive, PO Box C700, West Conshohocken, PA 19428-2959, United States (2007) 